\title{
Desafíos actuales para nuestro estudio dominicano*
}

\author{
P. Guido Vergauwen, O. P.**
}

\section{Resumen}

este escrito presenta una perspectiva amplia de la importancia del estudio en el contexto del pensamiento dominicano. estudiar y aprender en la espiritualidad dominicana hace parte del ser y el quehacer de un dominico, y de aquellos que se encuentran en la búsqueda apasionada de la verdad. Pero tal empeño en este camino implica superar los obstáculos del pluralismo y el fundamentalismo en el que parecen estar ciertas corrientes posmodernas de pensamiento que manifiestan una capitulación de la razón y el quiebre de las esperanzas y ambiciones iluministas de la modernidad. Por tal razón, es necesario redescubrir la comprensión de la verdad en la tradición dominicana y manifestarla principalmente mediante la predicación, el testimonio y la enseñanza a los demás.

Palabras clave: estudio, verdad, tradición dominicana, pluralismo, teología.

* Texto original preparado para el capítulo general de la Orden en Caleruega, españa (16 de julio-8 de agosto de 1995).

** Asistente del maestro de la Orden de Predicadores para la Vida Intelectual. 


\section{Estudiar y aprender}

¿qué quiere decir estudiar? ¿qué quiere decir aprender? De manera muy global y sin tener en cuenta las experiencias frustrantes o plenificantes que pueden estar ligadas al trabajo intelectual, podría decir que se trata de buscar comprender el sentido de las cosas, de las realidades que nos rodean, y que los estudios están orientados a la comunicación con las otras personas respecto de aquello que hemos descubierto como sentido, como verdad. A menudo, es luchar con el lenguaje para poder designar a través de nuestras palabras - tan adecuadamente como sea posible - la realidad tal como es. Cuando estudiamos, expresamos la confianza en que existe una verdad por buscar, un sentido por descubrir, en que disponemos de una razón que puede comprender y de una palabra que puede expresar lo que es. ¿es esto hoy verdaderamente así? ¿No nos hallamos enfrentados a un escepticismo muy difundido respecto de las posibilidades de un acercamiento intelectual a la realidad, es decir, con un antintelectualismo?

\section{Dos desafíos: pluralismo radical y fundamentalismo}

Me parece que hay aquí dos desafíos por enfrentar: se los podría designar como el desafío del pluralismo y el del fundamentalismo. Se trata de actitudes de vida y de comportamientos sociales y religiosos que manifiestan una capitulación de la razón y el quiebre de las esperanzas y ambiciones iluministas de la modernidad, de ambiciones de poder estructurar el mundo a partir de los esfuerzos de la razón y de la convicción de que esta constitución de un mundo "razonable" traería la libertad y el bienestar para todos, que el saber operaría de por sí la justicia. Pareciera que estas expectativas no se han realizado. Bastaría contemplar aquello que una vez Albert Camus, en un discurso a los dominicos de París poco después de la Segunda Guerra Mundial, llamó "la figura ensangrentada que ha tomado la historia de hoy" (p. 426). ¿Cómo creer aún en las posibilidades de la razón, en los esfuerzos del intelecto, frente a aquello que no se puede comprender: Auschwitz, Hiroshima, Soweto, Sarajevo, Ruanda, Burundi y tantos otros? Uno se encuentra 
tentado a hablar de una abdicación de la razón - y a huir hacia una visión radicalmente pluralista del mundo o hacia alguna forma de fundamentalismo-.

Estas dos reacciones a las deficiencias, y diría casi al fracaso de la modernidad, son una forma de resignación. Una resignación frente a las posibilidades humanas, siempre amenazadas, de descubrir la verdad por la vía de la razón. el pluralismo disuelve la verdad única en una multitud de opiniones o remite la decisión respecto de la adhesión a la verdad a un futuro indefinido. El fundamentalismo, por su parte, busca contrarrestar la debilidad de la razón por la apelación acrítica a una adhesión incondicional, fundada en las formas de mediación de la verdad. esta adhesión confunde las figuras terrestres de la verdad con la verdad misma. Las dos reacciones parten de una misma y falsa alternativa respecto de nuestro conocimiento de la verdad, que intentan resolver de manera opuesta: rechazando aceptar una verdad que se presenta en la historia y que encontramos como una exigencia que señala un camino (el pluralismo se refugia en la indecisión respecto de la verdad) o rechazando el esfuerzo de la búsqueda a través de un largo proceso crítico que implica también riesgos de error (el fundamentalismo se refugia en una concepción ahistórica de la verdad y de sus mediaciones).

Para una consideración pluralista del mundo la verdad se dice en plural. Ciertamente, hay que distinguir este pluralismo de la legítima pluralidad de la que habla la Ratio Studiorum Generalis de la Orden, al decir:

ya la misma Sagrada escritura ofrece una pluralidad de maneras de hablar por medio de las cuales Dios se ha revelado a los seres humanos, pluralidad que sigue existiendo en la Iglesia a lo largo de su historia. el mensaje divino, por tanto, tiene siempre necesidad de ser traducido e interpretado para que pueda ser recibido y anunciado a todos los seres humanos [...] la diversidad de seres humanos y culturas es un misterio que manifiesta el designio de Dios creador y salvador. Todo dominico debe, pues, estar atento desde el comienzo de su formación a la pluralidad de experiencias humanas de las que manan las diversas culturas (VII). 


\section{Pluralismo radical y comprensión religiosa}

Sobre la comprensión religiosa del mundo, el pluralismo radical - a menudo identificado con el concepto bastante vago de la posmodernidad - parece estar marcado por la convicción de que el único y gran relato, en el cual Dios quiere comunicar su verdad liberadora a los hombres, puede ser reemplazado por una multitud de relatos intercambiables entre sí. en esta óptica se espera alcanzar el fin de la tentación totalitaria que se instalaría cuando no hay si no un uno y único relato, una verdad, una sola interpretación válida, un único Dios verdadero.

De aquí en más se dirá: "A cada uno su verdad". es la verdad barata en el mercado libre de las posibilidades. Verdadero es aquello que agrada por el momento, lo que parece tener plausibilidad. Lo que acompaña al quiebre de los ambiciosos proyectos de la modernidad es una parcelización, una fragmentación del saber. este ya no se supone que conoce lo que es, sino que no tiene otra finalidad que ser útil, propicio a la carrera, y conforme con el nivel medio de las estadísticas. Los medios de comunicación social nos transmiten muy a menudo este saber fragmentado, tendenciosamente escogido y combinado, dándonos, al mismo tiempo, la impresión de expresar el todo, y sirviendo de hecho a los poderes dominantes y a los intereses del mercado. esta evolución conduce a una pérdida de la capacidad de admirarse, conduce a la curiosidad en lugar de la estudiosidad (cf. Santo Tomás, STh II-II, q 1óó y 1ó7). La ciencia queda sometida a la apariencia de una mezcla de citas; el debate sobre la reforma de estructuras y estatutos reemplaza la disputa sobre los contenidos.

\section{La tentación del fundamentalismo}

La tentación del fundamentalismo se explica en parte sobre el trasfondo de esta pérdida de identidades claras en el pluralismo, por la sospecha tan difundida de que todo puede ser diferente y de que los otros también podrían tener "cierta parte de razón". Se comprende a aquellos que se encuentran fatigados frente a una actitud que pone "a remate" la verdad, que la relega 
a experimentos pasajeros, y que deja las decisiones éticas a libre disposición del individuo.

en efecto, sobre todo, en el dominio de la fe religiosa, la verdad no puede ser expuesta a un proceso indefinido de prueba y error. La fe se expresa en la certeza, y el compromiso vive en el asentimiento más allá de la crítica y reclama la credibilidad de aquellos que la profesan. Pero el error del fundamentalismo religioso consiste, como acabo de decir, en que establece una falsa alternativa respecto de nuestro conocimiento de la verdad. O bien debemos buscar la verdad a través de un largo proceso crítico que implica riesgos de error, o bien no cabe sino aceptar de forma obediente esta verdad, tal como está contenida en la revelación divina, consignada en las escrituras y legitimada por la autoridad de la Iglesia docente. esta alternativa presupone que la Revelación, comprendida como una instrucción divina, nos da acceso inmediato a la verdad. excluye todo error y fundamenta una certeza absoluta bajo la forma de seguridades diversas: en cuanto al comportamiento moral, a los ritos por cumplir, al sistema en el cual uno encuentra su identidad, a las autoridades que hay que seguir.

\section{La Orden de Predicadores ante estos desafíos}

La comprensión de la verdad en nuestra tradición dominicana nos brinda puntos de referencia muy valiosos en un momento en que debemos ubicarnos entre estas dos tendencias sociales. La verdad a la cual nos adherimos no es plural, es única; es la verdad primera, Dios como principio y fin de todas las cosas, que se nos da a conocer en Jesús nuestro salvador. en él "se nos ha mostrado el camino de la verdad, por el cual nos es posible acceder a la resurrección y a la bienaventuranza de la vida inmortal" (Suma teológica, prólogo $\left.\mathrm{III}^{1}\right)$. esta verdad única no es un sistema de doctrinas, sino una persona, el camino hacia el Padre, el camino por el que los creyentes siguen al Hijo y a través del cual constituyen en el espíritu el signo visible de la comunión

1 Viam veritatis nobis in seipso demonsrabit per quam ad beatitudinem immortalis vitae resurgendo pervenire possimus. 
entre las personas divinas. Siguiendo este camino, nos hacemos testigos, predicadores del amor liberador de Dios. Conocer esta verdad no es poseerla como una moneda en el bolsillo, sino, ante todo, ser fascinado por un camino e identificarse con una persona. Es encontrar una nueva identidad hasta en el sufrimiento, "ya que también Cristo sufrió por vosotros, dejándonos ejemplo para que sigáis sus huellas" (1 Pedro 2, 21). ¿Cómo conocer esta verdad única y personal? ¿Cómo estudiarla si no es frecuentándola antes en la contemplación, viviendo de su vida y según su ejemplo, siguiéndola hasta el transfondo de los sufrimientos de nuestro tiempo?

La búsqueda de esta verdad implica aquello que Lacordaire llamaba "la grâce d'entendre ce siècle" (Lacordaire, p. 4); el diálogo crítico con el contexto dado, con las cuestiones sociales, los desafíos de la justicia y la paz; la búsqueda de esta verdad nos lleva a la solidaridad con los marginados y los olvidados. el fruto de esta búsqueda no es ante todo la especulación de la alta ciencia, sino la compassio. en este sentido, el estudio es para nosotros más que la mera adquisición de un saber: forma parte de la conversión permanente a la cual estamos llamados por nuestro compromiso religioso.

\section{¿Dónde se encuentra la verdad?}

¿Dónde se encuentra esta verdad que queremos buscar y cuyas huellas queremos seguir? el poeta sueco Tomas Tranströmer lo dice así: “La verdad está echada por el suelo, pero nadie la levanta. La verdad yace sobre la calle. Pero nadie la hace suya". ¿No reflejan acaso estas frases la intuición fundamental de Santo Domingo al llamar a la vida a la Orden de Predicadores, una orden de personas que en el seguimiento de la vida de los apóstoles recogen amorosamente esta verdad que yace en las calles, que no se descubre sino cuando uno se pone en camino, en una existencia de peregrino y mendicante, lejos de la estabilidad económica de las formas tradicionales de vida conventual monástica, en medio de la confusión de los nuevos movimientos religiosos y de una sociedad que busca estructuras democráticas de coexistencia? Esa es nuestra historia, nuestro origen; esa es nuestra tarea, presente en la misión de predicación. 
La verdad, no directamente en la forma perfecta de una definición acabada, sino buscada en el cuestionamiento de los hombres, en lo referente al fundamento de su esperanza. esta verdad hace posible la vida, ayuda a soportar los sufrimientos, promete la liberación. es una verdad que no enceguece, por la cual se lucha en las noches sin sueño y a través del peligro de muerte, una verdad que remueve la piedra de la entrada de tu tumba... (cf. poema de Ingeborg Bachmann Was wahr ist).

\section{Conocer la verdad...}

Conocer esta verdad es lo más importante para lo que nos hace aptos el espíritu de Dios.

eso es lo que dice Santo Tomás en su comentario al libro de Job. Totalmente en la línea del carisma de su Orden, subraya que el conocimiento de esta verdad implica un caminar: por nuestras propias fuerzas nosotros la alcanzamos solamente poco a poco, quasi pedetentim. es andando a pie como se encuentra esta verdad, en la impotencia del peregrino, no montado a caballo como los señores poderosos.

en la humanidad de Jesús, Dios ha dado a conocer la verdad de su Ser. Aquel que sigue esta verdad recibe estabilidad interior, solidez y consistencia (soliditas maxima est per veritatem). Pero precisamente esta verdad es expuesta a la disputatio. Incluso con Dios mismo puede el hombre disputar sobre la verdad; ella da la medida. En este debate sobre la verdad, todos son interlocutores en pie de igualdad (veritas ex diversitate personarum non variatur). es necesario combatir no solo los errores que conciernen a la veritas doctrinae, sino también aquellos que violan la veritas iustitiae.

esta manera de tratar la verdad, exponiéndola al debate y a la búsqueda de una comunicación sincera, es una herencia verdaderamente dominicana, surgida de una experiencia viviente con la forma democrática de la vida cotidiana y el carácter reformable de las reglas de nuestra vida común. es un conocimiento de la verdad que se expone en la práctica y que reconoce 
a esta su primacía criteriológica: "Prius vita quam doctrina. Vita enim ducit ad scientiam veritatis" ${ }^{2}$.

\section{Estudio y predicación}

ya he mencionado que el estudio es una parte esencial de nuestra identidad dominicana y que está directamente orientado a la salvación de las almas. Santo Domingo quería que sus frailes estudiaran incesantemente la Palabra de Dios, que fueran personas que escuchan la Palabra antes de predicarla a los otros, que esta Palabra transformara su vida y se encarnara en su comportamiento cotidiano. este estudio que Domingo quería recibió una dimensión eclesial y profética: se trataba de cultivar en la pluralidad de contextos, en el diálogo con las diferentes concepciones religiosas, esta inclinación por la verdad (propensio in veritatem) presente en cada ser humano, que hoy justamente parece estar amenazada.

el estudio y la proclamación de la Palabra están estrechamente ligados entre sí. Los dos reciben su luz y su fuerza del espíritu que Cristo resucitado nos envía desde el Padre. ellas nos hacen participar, por así decirlo, de la comunión de Dios mismo, pero exigen a su vez que demos forma entre nosotros a esta comunión. es la comunidad, no el individuo aislado, quien es sujeto del estudio y de la predicación. Además, la Palabra estudiada y predicada es celebrada en la liturgia común, en la oración comunitaria. La Palabra de la predicación (praedicare) es sostenida por la alabanza (laudare), y la admiración ante la gracia divina y el misterio de la bondad de Dios y su amor por los hombres (benedicere). esta admiración impulsa al estudio, se desarrolla en estudio. La búsqueda de la verdad en nuestra Orden vive, por tanto, de estos tres elementos: la oración sostiene el estudio y la alabanza de la grandeza divina inspira la palabra de la predicación.

2 Santo Tomás, Comentario al Evangelio de san Mateo. 


\section{Los estudios en la Orden}

Lo ideal es que el estudio pueda ser vivido como una empresa integral y colectiva que tiene su lugar natural en el centro de estudios de la Orden, eventualmente integrado en un centro universitario o afiliado a él. Debemos iniciar una reflexión nueva y profunda sobre la relación entre la formación básica de nuestros frailes y los estudios institucionales, para evitar frustraciones ulteriores y superar la separación artificial entre el curriculum de estudios y la preparación a la pastoral, entre predicadores-misioneros y profesores.

Pero cualquiera que sea el lugar donde nuestros hermanos reciban su formación y hagan sus estudios, es absolutamente necesario que aprendan a pensar de manera autónoma y crítica, a analizar y juzgar las situaciones y a hacer que surja la verdad en la disputatio: a utilizar su propia luz. esto implica de parte de los maestros que los acompañan una actitud discreta y humilde. Pensemos en ese dicho de la sabiduría judía: "el estudio de la Torá se parece a alguien que avanza en una noche oscura a través de un bosque espeso. Por un tiempo alguien te acompaña con una antorcha en la mano. Pero en el primer cruce te deja para seguir su camino, y tú debes continuar el tuyo a tientas. quien tiene su propia antorcha no necesita temer la obscuridad". esta actitud de humildad ante la verdad implica la voluntad de escuchar la sabiduría de la vida, gran paciencia y capacidad de compasión. No hay servicio a la verdad sin humanidad creíble, sin el realismo de la observación que se expresa en esta exhortación de San Pablo: "Mirad las cosas de frente" (2 Cor 10, 7).

\section{Continuación creativa de la tradición tomista}

Aquí podríamos situar nuestra manera creativa de continuar la tradición tomista. Dice el cardenal Congar en sus Entretiens d'automne:

¿qué es lo que debo a Santo Tomás y por lo cual he continuado frecuentándolo a menudo? - Ante todo una cierta estructura de espíritu. Allí reside aún hoy su actualidad: tener orden en las ideas, y también el sentido de la apertura y del diálogo. Pues Santo Tomás con su increíble 
capacidad dialéctica, ha pasado toda su vida buscando nuevos textos, procurándose nuevas traducciones, discutiendo con todos los interlocutores de su época: los judios, los musulmanes, los averroístas, los agustinianos, etc. el tomismo es la apertura al diálogo (1987, p. 91).

A continuación, el autor sostiene que gracias a su estudio de la historia y a la práctica del ecumenismo ha aprendido a ver de otro modo la estructura interna del tomismo:

Amo estas palabras de Péguy a condición de comprenderlas bien: "no lo verdadero, sino lo real". He consagrado mi vida a la verdad, he creído mucho en ella, ella ha sido la reina de mi vida. A menudo he escrito en el encabezamiento de mis textos: "Veritas, domina mea", y he citado las palabras de madame Swetchine: "he amado la verdad como se ama, con todo el ser, a una persona". Tomó muy a pecho lo verdadero, pero lo real; es decir, lo verdadero con la historicidad, con su estado concreto en el devenir, en el tiempo, lo cual es otra cosa. esto es muy importante, pues el tomismo que algunos han sostenido, o quizás aún sostienen, está en el fondo en continuidad con Parménides: una filosofía de la identidad; en tanto que Santo Tomás con la potencia y el acto tiene una concepción dinámica del ser (p. 91).

\section{Algunas intuiciones básicas de nuestro estudio}

A continuación, formularé algunas intuiciones básicas que puedan guiar nuestro trabajo teológico en la línea de esta tradición tomista, que son también dominios de investigación teológica que podríamos promover en un diálogo con los desafíos de hoy:

- La teología que nos prepara a la proclamación multiforme de la verdad debe concentrarse de forma consecuente en el misterio de Dios para hacernos capaces de distinguir al Dios verdadero de los ídolos que dominan nuestras sociedades: el mercado total, el nacionalismo.

Debemos recordar continuamente que esta verdad nos es manifestada en la humanidad del Verbo. es una verdad que se encarna, que quiere tomar 
cuerpo en la vida de los hombres y mujeres para hacer nacer en ellos la verdadera libertad, la solidaridad con los que sufren, el amor por la justicia. es una verdad que crea una comunión en el espíritu, una fraternidad en la que las divisiones de raza, sexo y clase pueden desaparecer ante la unidad que formamos a través del bautismo.

La teología debe respetar claramente el trabajo de la razón que opera en una fe que busca comprender. ella no es el fruto de una inspiración carismática, sino el resultado del estudio (per studium habetur). De este modo, esta será y permanecerá humana, frágil, corregible. Será un servicio a la esperanza.

Solamente bajo esta condición podemos evitar la situación mencionada en $2 \operatorname{Tim} 3,7:$ " [...] siempre están aprendiendo y no son capaces de llegar al pleno conocimiento de la verdad". Pero esta razón debe ser una razón amante, una razón con corazón. Una teología "razonable" respetará las posibilidades, los peligros y los límites del lenguaje. Sabrá callar en el momento oportuno, pues "hay un silencio que revela al hombre sensato"3.

- Nuestra teología respetará la autonomía de la realidad creada y la bondad fundamental de la creación. esto nos debe conducir a apreciar profundamente el valor de la realidad humana finita como signo del amor creador divino entre nosotros. Será una teología abierta a las culturas que son precisamente el fruto de la intervención humanizante y libre de los hombres en la naturaleza creada. Pero en este mismo contexto nuestra teología no deberá olvidar las consecuencias catastróficas para los hombres y mujeres, y para la naturaleza, de un cierto tipo de dominación y explotación humana. Nuestra teología debe perder la inocencia cognitiva y hacer memoria de las víctimas de la historia, de sus sueños no realizados de libertad, de sus sufrimientos injustos. Debe aprender a leer la historia del revés y a descubrir que la verdad no es siempre propiedad exclusiva de los vencedores, sino más bien, más a menudo, de los vencidos.

- Nuestra teología es desde sus orígenes una teología de la ciudad. Santo Domingo envió a sus hijos a las ciudades nacientes y a sus

3 Sir 20,1; cf. también Sir 20,7 y Qo 3,7. 
universidades, con su brisa de aire fresco y sus tempestades de querellas ideológicas acerca de las nuevas filosofías paganas. Su lugar de inserción es la ciudad, la sociedad humana en sus luchas por la justicia y la paz, los derechos humanos, el lugar de nacimiento de las nuevas democracias y del aprendizaje de vivir con las minorías. Por ello es importante que nosotros integremos en nuestros estudios la filosofía, el análisis social, los aportes de las ciencias humanas, para que sean instrumentos que nos ayuden a comprender las situaciones en las cuales proclamamos la Palabra. Digo conscientemente "instrumentos" y no instancias ante las cuales la consideración teológica de la realidad debiera justificarse en su identidad. Es más bien al contrario; a este respecto puede aconsejarse siempre la lectura de aquel bello texto de Santo Tomás en su comentario In Boethii de Trinitate, donde se plantea la cuestión "Utrum in scientia fidei, quae est de Deo, Iiceat rationibus philosophicis uti". Santo Tomás subraya entre otras cosas que es erróneo utilizar la filosofía como si "quae sunt fidei includantur sub metis philosophiae; ut si nihil aliquis credere velit nisi quod per philosophiam haberi potest". (Santo Tomás de Aquino, p. 375). y en el ad quíntum formula esta frase bien conocida: "IIIi qui utuntur philosophicis documentis in sacra scriptura redigendo in obsequium fidei, non miscent aquam vino, sed convertunt aquam in vinum".

- Nuestra teología deberá ser ante todo una teología bíblica, profundamente anclada en la tradición eclesial y alimentada de la meditación, más aún, de la celebración de la Palabra. en esta línea, debe ser naturalmente ecuménica, abierta a otras tradiciones cristianas, dispuesta a aprender de su testimonio. Debe ser cristiana y no negar sus raíces judías; capaz de dejarse interrogar por la realidad judía y acerca de su vitalidad después de Cristo.

\section{Estudio y esperanza cristiana}

No quiero entrar aquí en la discusión acerca de la organización concreta de nuestros estudios y de la formación en general. Cada entidad ha hecho o 
bien se encuentra haciendo la adaptación local de la Ratio Formationis Generalis (RFG) y la Ratio Studiorum Generalis (RSG). Creo que globalmente hablando, el tema de la formación permanente de los frailes plantea dificultades y merecería ser examinado más detenidamente. Se trata de saber cómo nuestras comunidades pueden llegar a ser verdaderamente lugares de estudio y de formación.

Para terminar, comparto una última reflexión concerniente a una caracteristica fundamental de nuestros estudios. Me gusta situar nuestra formación intelectual en la línea de 1 Pedro 3, 15s: "Santificad a Cristo el Señor en vuestros corazones, siempre dispuestos a dar respuesta a todo el que os pida razón de vuestra esperanza. Pero hacedlo con dulzura y respeto".

Creo cada vez más que debe haber una relación profunda entre nuestro esfuerzo en comprender la verdad de la Palabra y la justificación de nuestra esperanza en un mundo de lucha con un profundo sentimiento de desesperanza a causa de la no realización de tantas esperanzas relativas a la libertad, la justicia, la desaparición de las formas de discriminación. La verdad que buscamos, estudiamos y proclamamos funda la esperanza, hace nacer en las personas que se adhieren a ella la plenitud de vida que nos promete, una vida en abundancia. es, en efecto, una esperanza inaudita la que Jesús formula al decir: "Si alguno guarda mi palabra, no verá jamás la muerte" (Juan 8, 52).

Estudiar es contribuir a una vida plena de esperanza; es generar la esperanza y la libertad que vienen del conocimiento de la verdad (cf. Juan 8,31). No olvidemos que las palabras de Jesús que nos transmite el evangelio de san Juan son proclamadas en una situación en la que Jesús es amenazado de muerte, y que la carta de Pedro, una pastoral sobre la esperanza, se dirige a una comunidad cristiana que es una minoría perseguida. La exhortación a la paciencia, la alegría y la confianza, a una esperanza justificada, no es válida sino en la medida en que anima a los cristianos a seguir las huellas de Jesús. Nuestro testimonio como predicadores se convierte así en un servicio humilde y modesto para la construcción de esta comunión eclesial que el Padre de nuestro Señor Jesucristo, en su gran misericordia, hace renacer para una esperanza viva.

Al final de sus Entretiens d'automne (1991), Congar subraya cómo él asume su parte de sufrimiento, por la cual se sabe unido al cuerpo místico del 
Señor Jesús. Su vida de teólogo dominico se había transformado enteramente en una presencia sufriente para todos los miembros del Cuerpo Místico: su teología era "intercesión, consolación, acción de gracias". esto es ciertamente lo esencial de nuestros estudios y lo que verdaderamente permanece de nuestra predicación.

\section{Referencias}

Congar, y. M. (1987). Entretiens d'automne. París: Éditions du Cerf.

Camus, A. (1961). El incrédulo y los cristianos. en Obras completas (t. 2). México: Aguilar. Lacordaire, H. D. Correspondance (t. 1). París: Éditions Universitaires Fribourg, Suisse-Éditions du Cerf.

Ordinis Fratrum Praedicatorum (1993). Ratio Studiorum Generalis. Roma: OP ediciones.

Santo Tomás de Aquino (1858). Opuscules de saint Thomas D'Aquine. París: Librairie de Louis Vives.

Santo Tomás de Aquino. Catena Aurea, Comentario al Evangelio según san Mateo. Incunable. Orden de Predicadores.

Tranströmer, T. (2010). El cielo a medio hacer (trad. Mascaró, R.). Madrid: Nórdica Libros. 